\title{
Theoretical Study of Energy Gap for Silicon and Germanium Under High Pressure
}

\author{
Khaled S. Hameed \\ Adnan M. AL-Sheikh \\ Department of Physics \\ College of Science \\ Mosul University
}

(Received 8/11/2010; Accepted 21/2/2011)

\begin{abstract}
In this study the energy gap $\left(\mathrm{E}_{\mathrm{g}}\right)$ for both silicon and germanium under high pressure and different temperatures is evaluated using two approaches. One of them by evaluating the gradient of $\left(\mathrm{E}_{\mathrm{g}}\right)$ with pressure $\left(\mathrm{dE}_{\mathrm{g}} / \mathrm{dP}\right)$, and with temperature $\left(\mathrm{dE}_{\mathrm{g}} / \mathrm{dT}\right)$ under different pressures. The other, by using different equation of state (Birch-Murnaghan, Misra-Goyal, Vinet and modified Lennard-Jones) to evaluate the variation of lattice constant with pressure, and then evaluate the variation of $\left(\mathrm{E}_{\mathrm{g}}\right)$ with pressure.
\end{abstract}

\section{درلسة قاربة الفجوة لالفة للسليكهن و الجرمانيوه تحت الضظط الهالي}

\section{الملغص}

مُ في هذا البحث هسلب فجوة الطاقة للكل من للسليكون و الجرمانيوم تحت ال ـضغط الع الي وعذ ـد

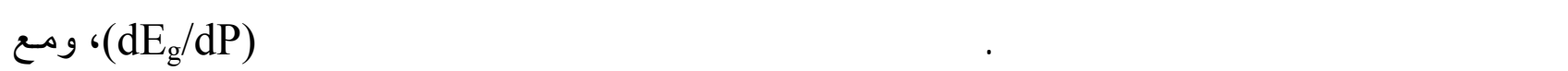

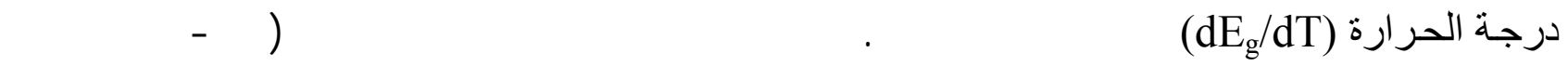
ميسرا - كويل، فينت ولينارد - جونس المطورة) لمسلب تغير ثلبت المبيكة مع الضغط، ومن ثم هسلب تغغير فجوة الطاقة مع الضغط.

\section{INTRODUCTION}

The high pressure investigation of semiconductors have become a focus area in condensed matter physics because of their tunable optical and electronic properties (Brad et al., 2010). As the band gap energy of semiconductors plays a fundamental role in electrical and optical properties, it is important and necessary to investigate the band gap change in order to get better understanding of their relevant properties. Thus, it is a significant way to understand the modification of band gap of semiconductor under external pressure. (Ouyang et al., 2009). 


\section{Silicon and Germanium}

All Group IV semiconductors ( $\mathrm{C}, \mathrm{Si}$ and $\mathrm{Ge}$ ) has the diamond crystal pattern as crystal structure. The tetrahedral configuration is typical of the bonding in the Group IV elements. Each of the atoms at the tetrahedron corners is shared by four primitive cells, so that this set of atoms contributes a total of one atom to the primitive cell. On adding to it the atom at the center we arrive at a count of two atoms per primitive cell. We thus have a lattice with basis.

The electron configuration of silicon in its ground state is $1 s^{2} 2 s^{2} 2 p^{6} 3 s^{2} 3 p^{2}$ but its normal valence state arises when one of the $3 s$ electron is promoted to a $3 p$ level thus giving the fourvalent configuration $1 s^{2} 2 s^{2} 2 p^{6} 3 s 3 p^{3}$. The tetrahedral $s p^{3}$ hybrids are responsible for the tetrahedral configuration of the crystal structure. The states $\left(1 s^{2} 2 s^{2} 2 p^{6}\right)$ have all large negative energies and they can be regarded as core states that do not take part in the band structure.

In the same way the electron configuration of germanium in its ground state is $1 s^{2} 2 s^{2} 2 p^{6} 3 s^{2} 3 p^{6} 3 d^{10} 4 s^{2} 4 p^{2} \quad$ which becomes in the $\mathrm{Ge}$ crystal $1 s^{2} 2 s^{2} 2 p^{6} 3 s^{2} 3 p^{6} 3 d^{10} 4 s 4 p^{3}$. (Altmann, 1991).

\section{Band Structure in Si and Ge}

One of the most important reasons for computing band structures is to determine the band gap i.e. the difference between the highest valence band and the lowest conduction band energies, since this can provide insight into potentially useful materials for optical device application (Rushton, 2002).

An ideal semiconductor band structure at $0 \mathrm{~K}$ is characterized by a completely filled valence band and a completely empty conduction band; the two are separated by a band gap, in which there are no allowable states. (Giovane, 1998).

The energy-momentum relationship for Si and Ge are shown in (Fig.1 and Fig.2). Both of these semiconductors are categorized as indirect gap semiconductors because the transition from energy maximum in the valence band to the energy minimum in the conduction band does not conserve momentum unless a third particle, such as phonon, is emitted or absorbed.

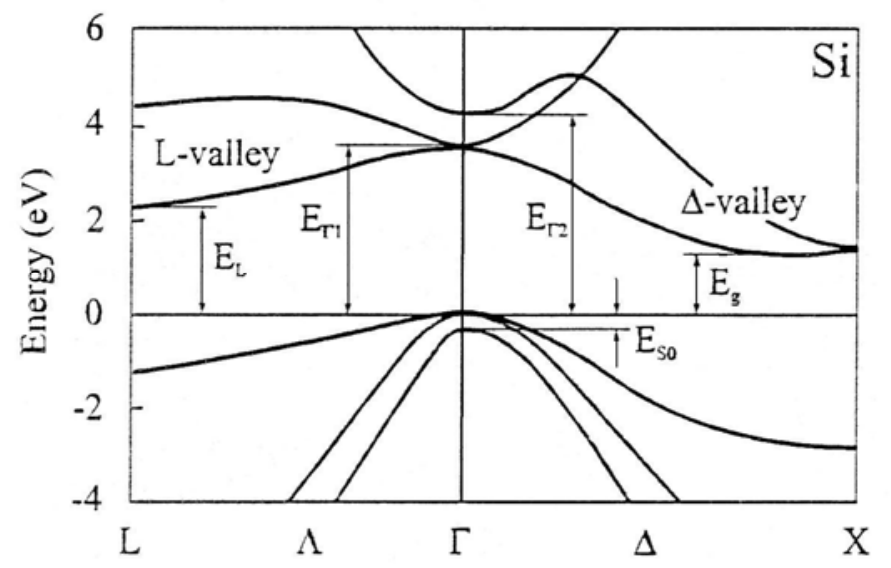

$300 \mathrm{~K}$

$\mathrm{E}_{\mathrm{g}}=1.12 \mathrm{eV}$

$\mathrm{E}_{\mathrm{L}}=2.0 \mathrm{eV}$

$E_{\Gamma_{1}}=3.4 \mathrm{eV}$

$E_{\mathrm{T} 2}=4.2 \mathrm{eV}$

$\mathrm{E}_{\mathrm{s} 0}=0.044 \mathrm{eV}$

Fig.1: Band structure of Si. (Levinshtein et al., 2001). 


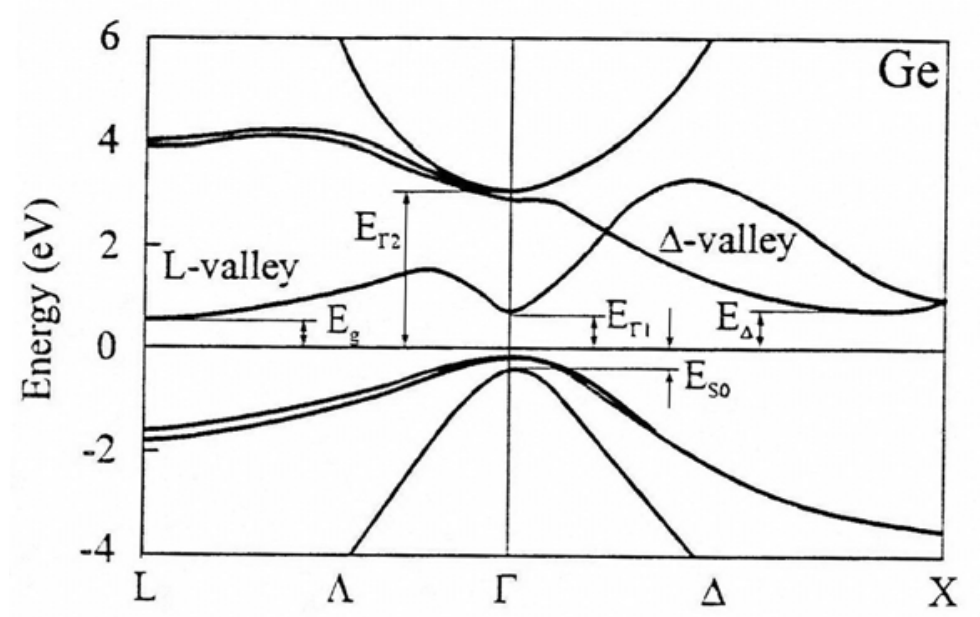

$300 \mathrm{~K}$

$\mathrm{E}_{\mathrm{g}}=0.66 \mathrm{eV}$

$E_{\Delta}=0.85 \mathrm{eV}$

$E_{\Gamma 1}=0.8 \mathrm{eV}$

$\mathrm{E}_{\mathrm{r} 2}=3.2 \mathrm{eV}$

$E_{\mathrm{s} 0}=0.29 \mathrm{eV}$

Fig.2: Band structure of Ge. (Levinshtein et al., 2001).

\section{Effect of Pressure and Temperature on the Energy Gap}

Two approaches have been used in studying the effect of pressure and temperature on the band gap of Si and Ge.

One of them by evaluating $\left(\mathrm{E}_{\mathrm{g}}\right)$ with pressure and temperature using the following equation. (Arezky et al., 2009).

$$
E_{g}(P, T)=E_{g}(0)+\alpha P-\frac{k T^{2}}{T+c}
$$

where $E_{g}(0)$ is the energy gap at $P=0$ and $T=0 . \alpha$ is the pressure coefficient $\left(d E_{g} / d P\right) . k$ and $c$ are temperature coefficients.

If we put $P=0$ in Eq.(1) we will have

$$
E_{g}(T)=E_{g}(0)-\frac{k T^{2}}{T+c}
$$

Eq.(2) is the same equation displayed by (Varshni 1967), and if we put $T=0$ we will have

$$
E_{g}(P)=E_{g}(0)+\alpha P
$$

Eq.(3) is the same equation displayed by (Levinshtein et al., 2001).

Using Eq.(3) with the values of $E_{g}(0)$ and $\alpha$ from table (1) we can plot the variation of the energy gap with pressure for Ge and $\mathrm{Si}$, as shown in (Fig.3 and Fig.4), which show the difference between the effect of pressure on the energy gap of the two elements although both of them belong to the same group of the periodic table, and they have the same crystal structure.

Table1: values of $E_{g}(0)$, pressure coefficient $\alpha$ and temperature coefficients $K$ and $c$ for $\mathrm{Si}$ and Ge. (Levinshtein et al. ,2001)

\begin{tabular}{|c|c|c|c|c|}
\hline Material & $\boldsymbol{E}_{\boldsymbol{g}}(\mathbf{0}) \mathbf{e V}$ & $\boldsymbol{\alpha} \times \mathbf{1 0}^{-3} \mathbf{e V} / \mathbf{k b a r}$ & $\boldsymbol{K} \times \mathbf{1 0}^{-4} \mathbf{e V} / \mathbf{K}$ & $c \mathbf{K}$ \\
\hline $\mathrm{Si}$ & 1.17 & -1.4 & 4.73 & 636 \\
\hline $\mathrm{Ge}$ & 0.742 & 5.1 & 4.8 & 235 \\
\hline
\end{tabular}




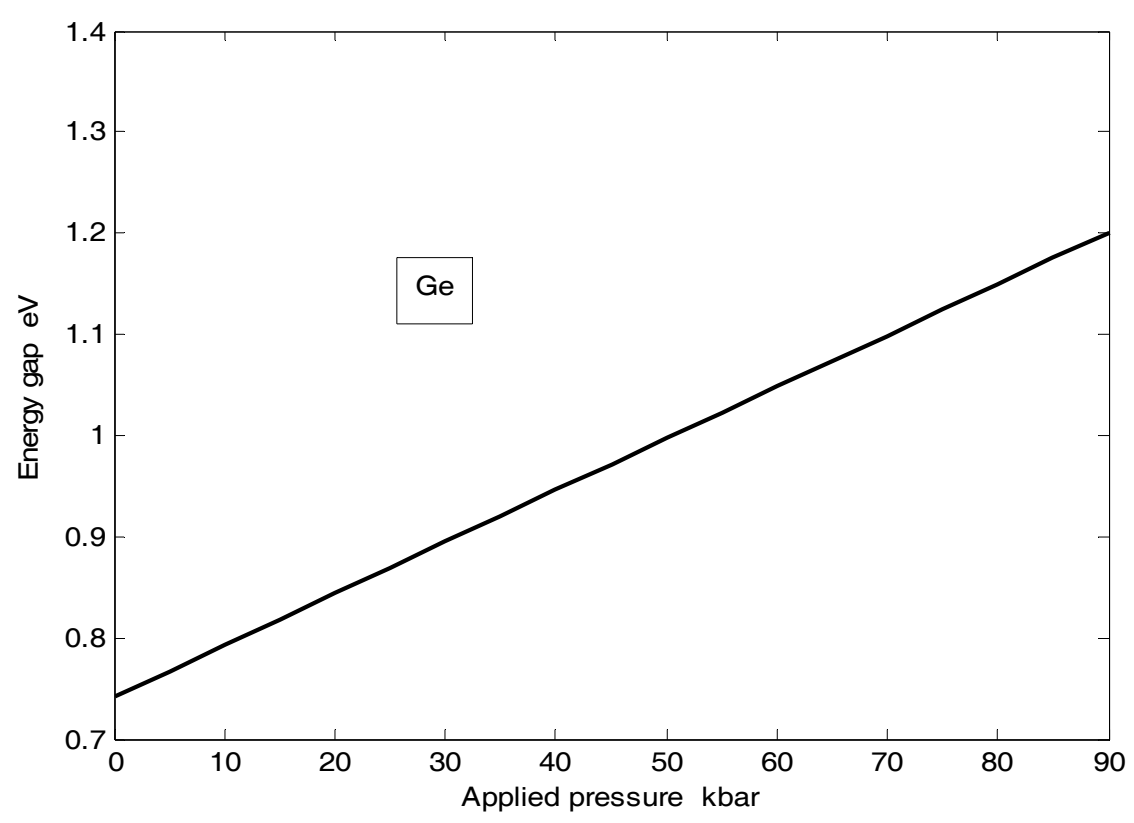

Fig.3: The variation of the energy gap with high pressure for Ge using Eq.(3).

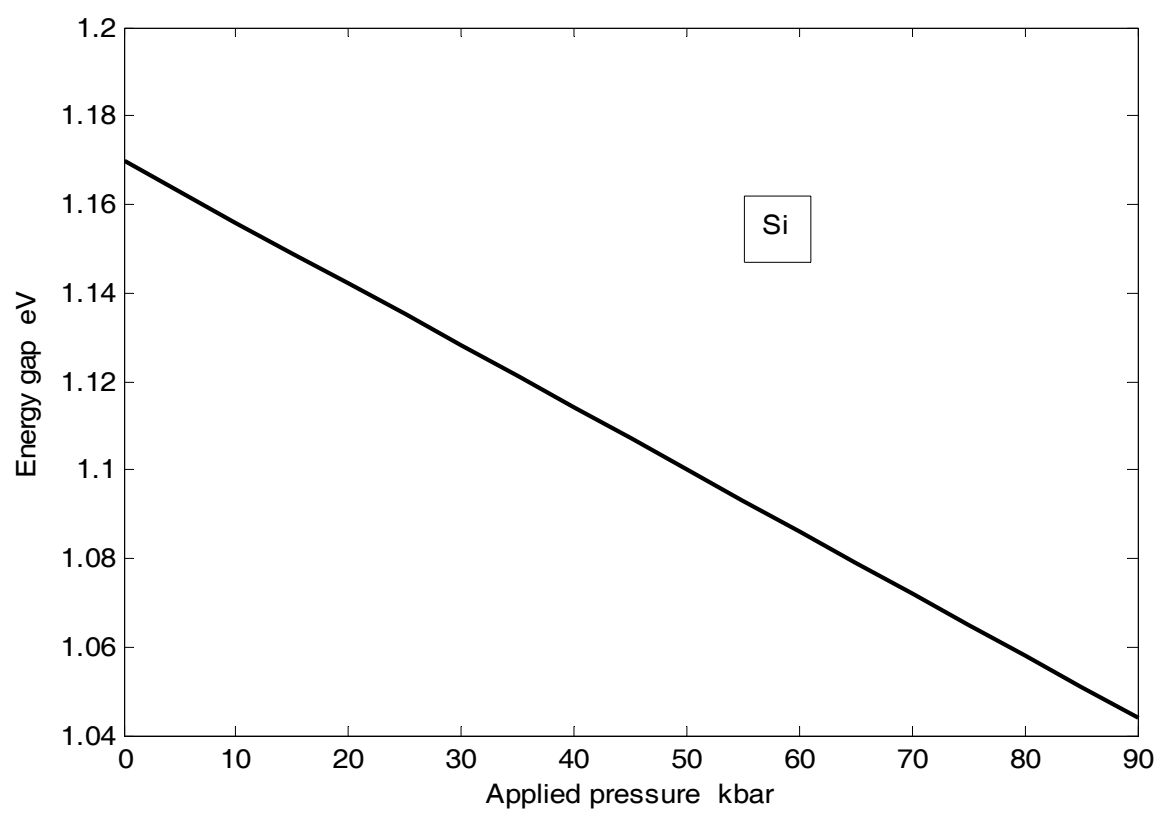

Fig.4: The variation of the energy gap with high pressure for Si using Eq.(3).

It is seen from Fig. 3 that the energy gap increases with increasing pressure in Ge while decreases with increasing pressure in Si (Fig.4). In other words the pressure coefficient $(\alpha)$ for $\mathrm{Si}$ is negative and for $\mathrm{Ge}$ is positive. The difference of the values of $\alpha$ depends on the type of transition, e.g. for the $\Gamma_{\mathrm{v}} \rightarrow \mathrm{L}_{\mathrm{c}}$ transition $\alpha$ is about $(5 \mathrm{meV} / \mathrm{kbar})$ as in Ge, while for $\Gamma_{\mathrm{v}} \rightarrow \mathrm{X}_{\mathrm{c}}$ transition $\alpha$ is about ( -1 to $-2 \mathrm{meV} / \mathrm{kbar}$ ) as in Si. (Wei and Zunger, 1999).

The negative value of $\alpha$ in Si can be explained (Lee et al., 1985) as the strong influence of the $d$ levels that lie in energy well above the $\mathrm{X}$ maxima of the conduction band. These levels repel the conduction band at $X$, forcing it downward in energy (relative to the minimum at $\Gamma$ ). 
The other approach is to evaluate the variation of $E_{\mathrm{g}}$ with pressure using lattice constant $a(P)$, Murnaghan equation of state (EOS), and the the following equation displayed by(Angilella et al., 2008).

$$
E_{g}=A\left(1-\sqrt{\frac{a(P)}{a_{c}}}\right)^{\gamma}
$$

where $A, a_{c}$ and $\gamma$ are fitting parameters and their values are:

$A=50.21 \mathrm{eV} \quad, \quad a_{c}=6.7797 \stackrel{\circ}{\mathrm{A}}, \quad \gamma=1.71675$

$$
a(P)=a(0)\left(1+\frac{B_{o}^{\prime}}{B_{o}} P\right)^{-\frac{1}{3 B_{o}^{\prime}}}
$$

$a(0)_{S i}=5.38 \AA, a(0)_{G e}=5.727 \AA \quad$ (Rushton, 2002).

$B_{o}$ and $B_{o}^{\prime}$ are the bulk modulus and its first-order pressure derivative at zero pressure.

Eq.(5) is Murnaghan EOS and the quantity $\left(1+\frac{B_{o}^{\prime}}{B_{o}} P\right)^{-\frac{1}{B_{o}^{\prime}}}$ represents $\frac{V_{P}}{V_{o}}$, and the variation of the lattice parameter with pressure can be written in general as:

$$
a(P)=a(0)\left(\frac{V_{P}}{V_{o}}\right)^{\frac{1}{3}}
$$

By substituting the values $(1 \rightarrow 0.91)$ for $\left(V_{P} / V_{o}\right)$ to evaluate the pressures then using Eq.(5) to find the lattice constant variation with pressure, then evaluate the variation of the band gap energy with pressure using Eq.(4). The results are shown in (Fig. 5 and 6).

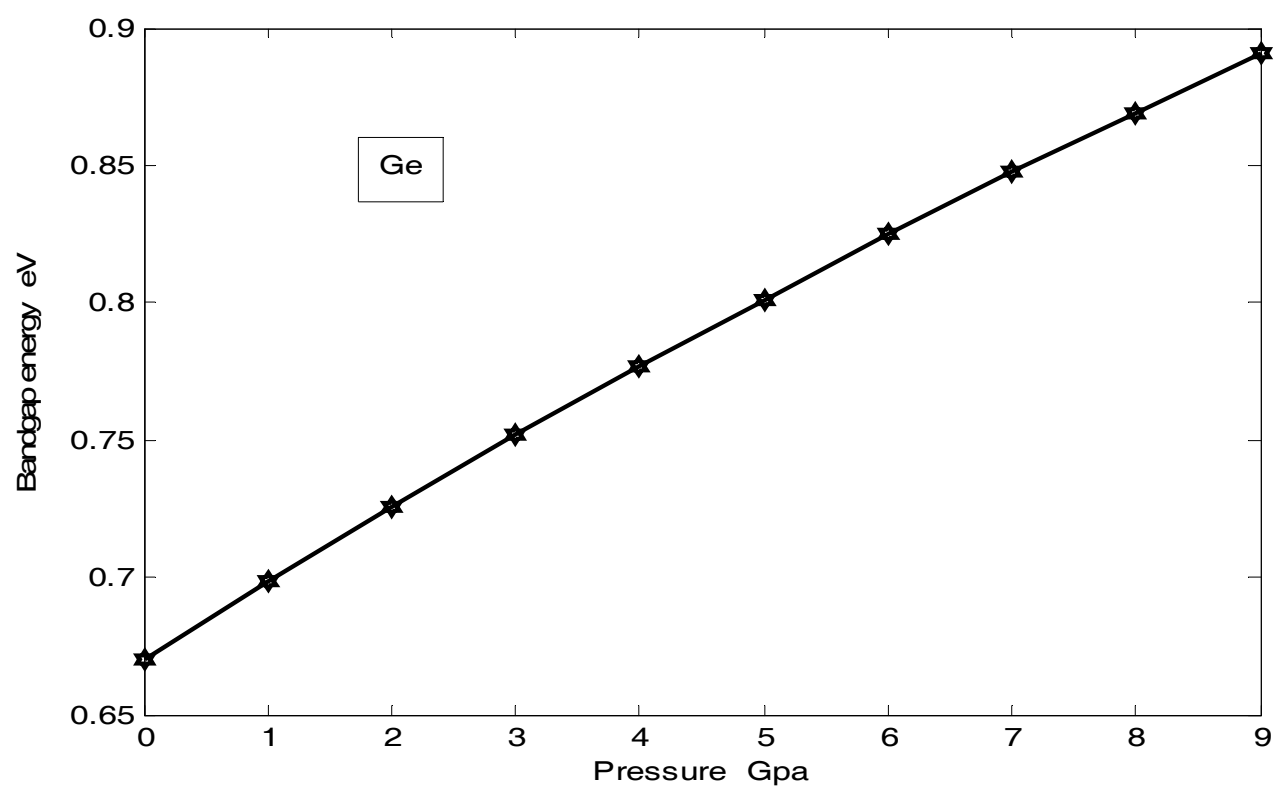

Fig.5. The variation of the band gap energy with pressure using Eqs.(4) and (5) for Ge. 


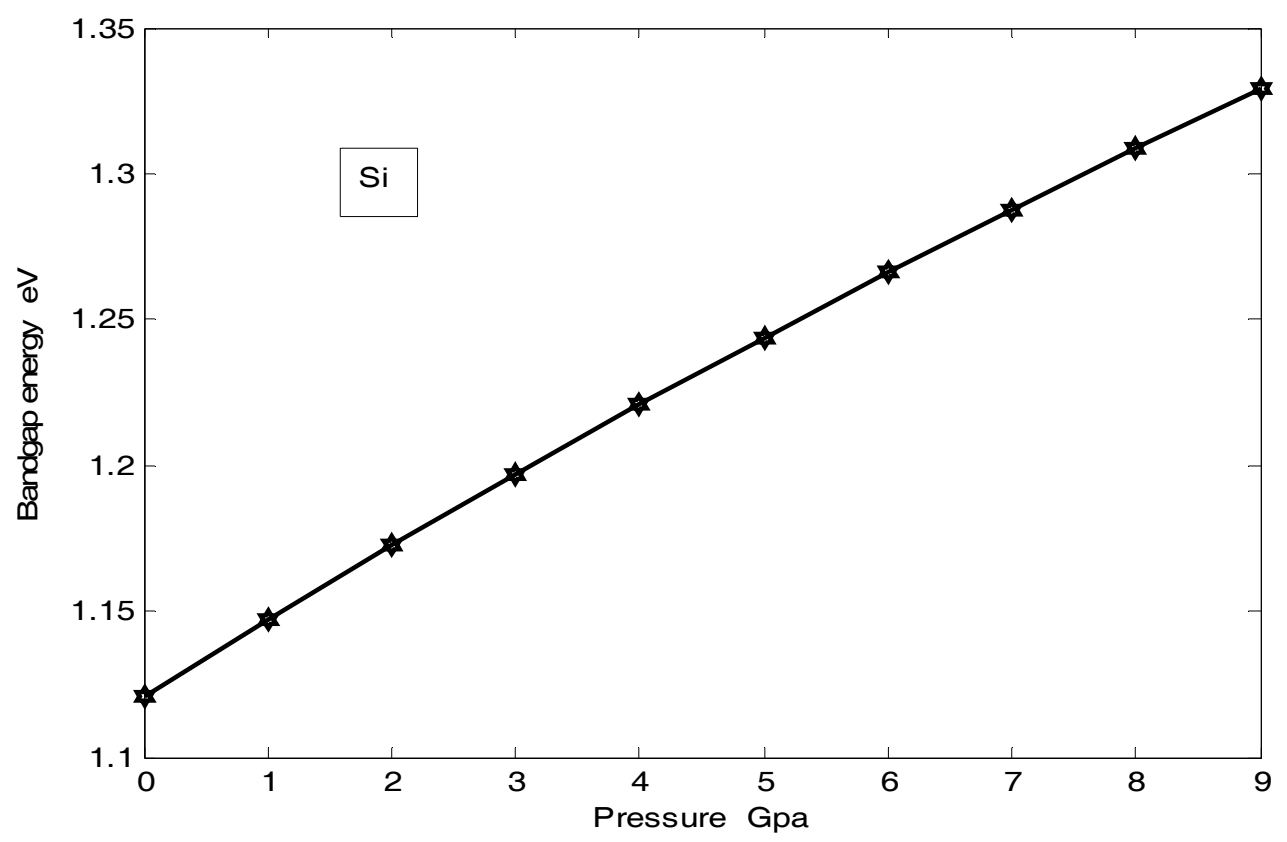

Fig.6. The variation of the band gap energy with pressure using Eqs.(4) and (5) for Si.

Since Eq.(6) represent the general form of the variation of lattice parameter with pressure, we found that it is suitable to evaluate the variation of lattice parameter using Birch-Murnaghan, Misra-Goyal, Vinet and modified Lennard-Jones EOSs, then evaluate the variation of the energy gap with pressure:

The modified Generalized Lennard -Jones equation of state (mGL-JEOS) is (Jiuxun S., 2005).

$$
P_{L J}=\frac{B_{o}}{n}\left(\frac{V_{o}}{V_{p}}\right)^{n}\left[\left(\frac{V_{o}}{V_{p}}\right)^{n}-1\right]
$$

where $n=\frac{1}{3} B_{o}^{\prime}$

The Misra - Goyal EOS is (Tripathi et al., 2006)

$$
P_{M G}=\frac{B_{o}}{20}\left[\alpha\left\{6 \eta^{-2}-15 \eta^{-5 / 3}+10 \eta^{-4 / 3}-\eta^{-1 / 3}\right\}+\beta\left\{3 \eta^{-2}-5 \eta^{-4 / 3}+2 \eta^{-1 / 3}\right\}+\delta\left\{\eta^{-2}-\eta^{-1 / 3}\right\}\right]
$$

with $\alpha=6+9 B_{o} B_{o}^{\prime \prime}+\left(3 B_{o}^{\prime}-4\right)\left(3 B_{o}^{\prime}-7\right), \quad \beta=2\left(3 B_{o}^{\prime}-7\right), \quad \delta=12, \quad \eta=\frac{V_{p}}{V_{0}}$

$B_{o}^{\prime \prime}$ is the second pressure derivative of $B_{o}$. 
The Birch-Murnaghan EOS is (Birch, 1947; Tripathi et al., 2006).

$$
P_{B M}=\frac{3 B_{o}}{2}\left[\eta^{-7 / 3}-\eta^{-5 / 3}\right]\left[1+\frac{3}{4}\left(B_{o}^{\prime}-4\right)\left(\eta^{-2 / 3}-1\right)\right]
$$

The Vinet EOS is (Vinet et al., 1986)

$$
P_{V}=3 B_{o} \eta^{-2 / 3}\left(1-\eta^{1 / 3}\right) \exp \left[\left\{\frac{3}{2}\left(B_{o}^{\prime}-1\right)\right\}\left\{1-\eta^{1 / 3}\right\}\right]
$$

The results of using the above EOSs with Eq.(4) and (5) are shown in (Fig.7 and 8).

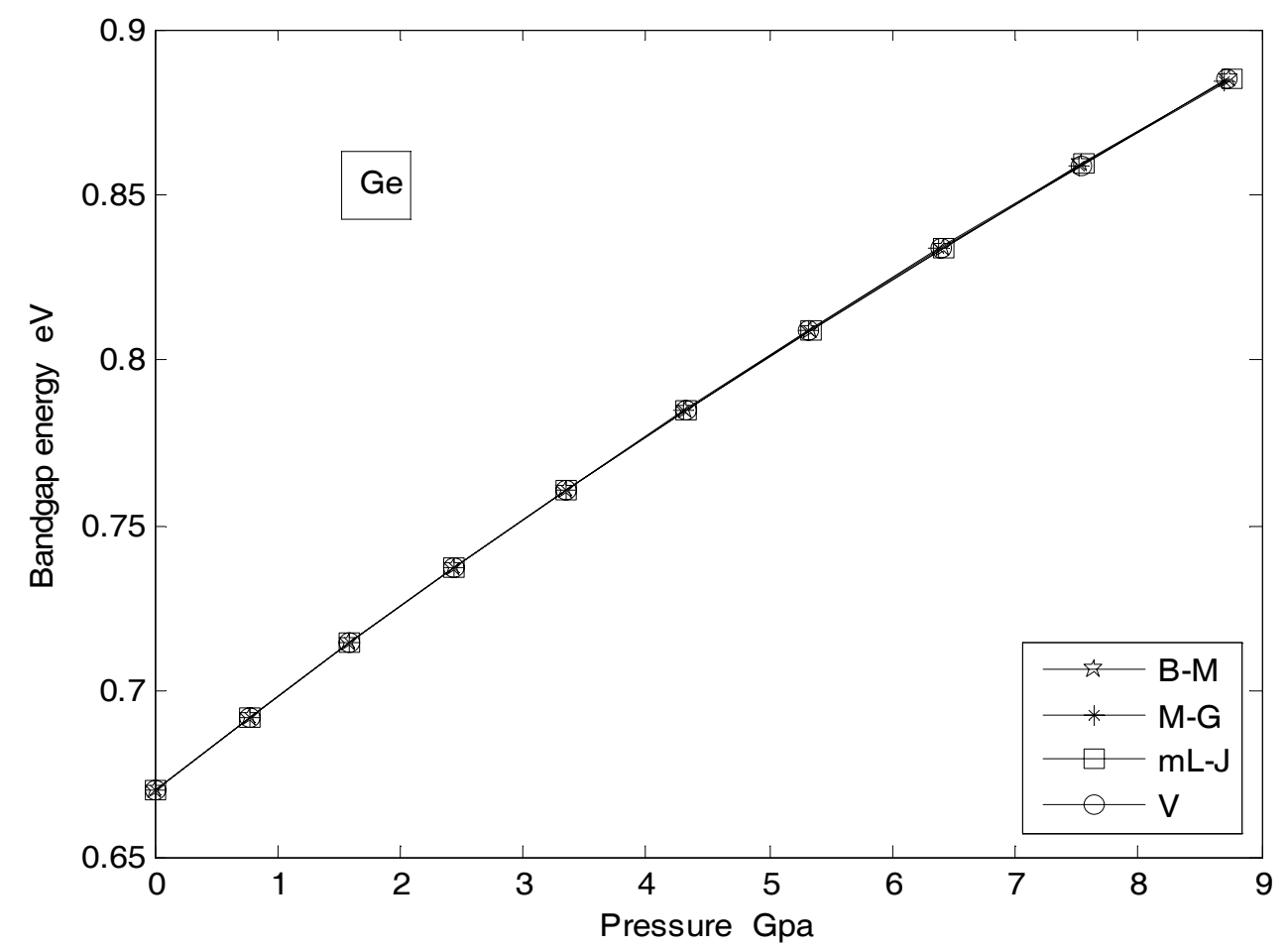

Fig.7: Variation of the bandgap energy with pressure from different EOSs using Eqs.(4) and (5) for Ge. 


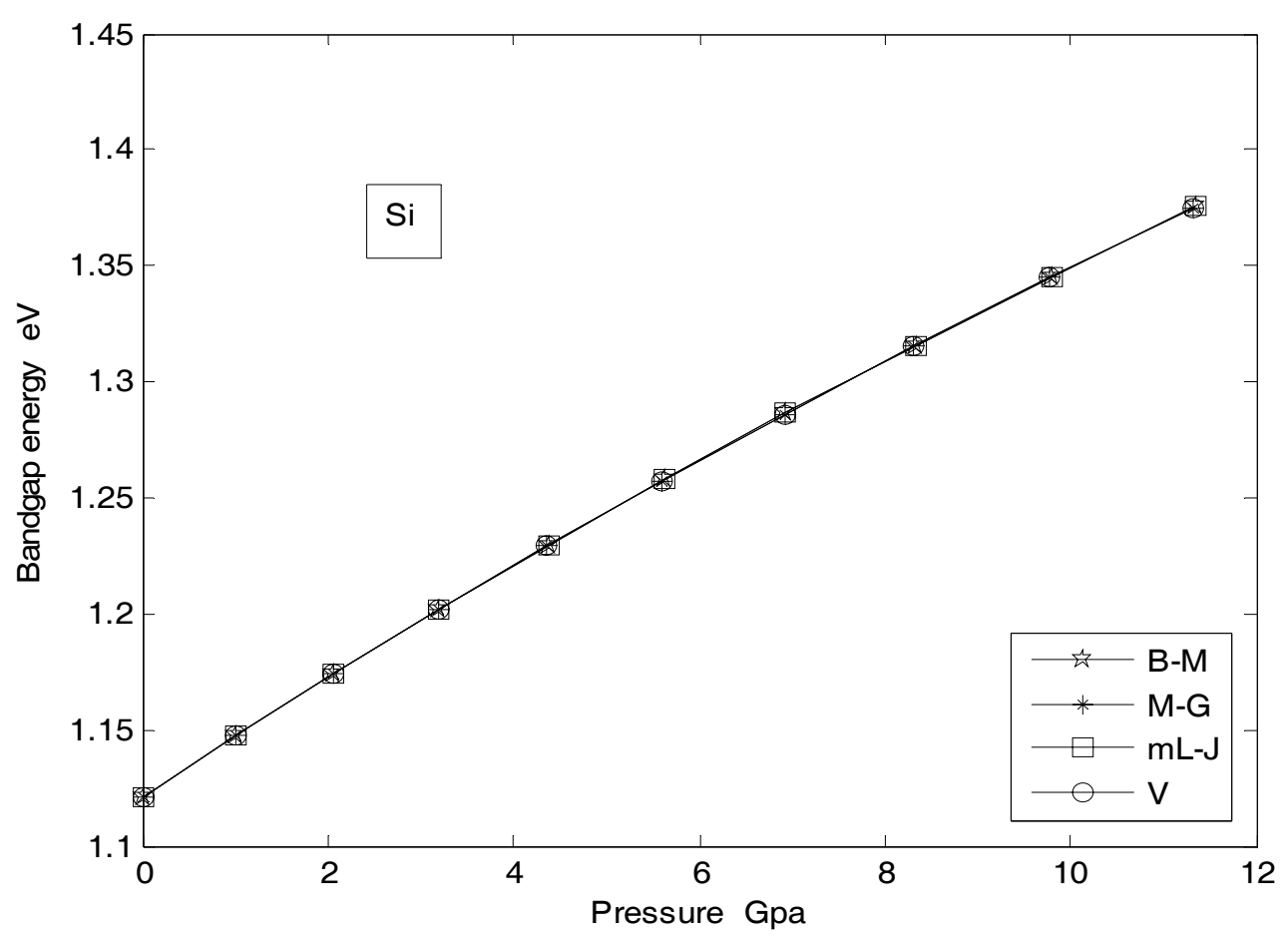

Fig.8: Variation of the bandgap energy with pressure from different EOSs using Eqs.(4) and (5) for Si.

Comparing the variation of $E_{g}$ with $P$ in Fig.(5, 7 for $\mathrm{Ge}$ and 6,8 for $\mathrm{Si}$ ) with results shown in Fig.( 3 for Ge and 4 for $\mathrm{Si}$ ) we can see that:

1- Evaluation of the variation of $E_{g}$ with $P$ using the equation given by (Angilella et al., 2008) i.e. Eq.(4) does not take into account the negative sign of the pressure coefficient for $\mathrm{Si}$, so that $E_{g}$ increases with increasing $P$ for $\mathrm{Si}$ using this approach (Fig. 8) which does not agree with the results of (Fig. 4) We conclude that this approach is valid for semiconductors with positive pressure coefficient only.

2- (Angilella et al., 2008) considered that Grüneisen parameter $(\gamma)$ has the same value for Si and $\mathrm{Ge}$ and that it is constant at different pressures, in fact $\gamma$ has different values for $\mathrm{Si}$ and Ge and it changes under different pressures. (Al-Sheikh et al., 2006).

\section{Calculations of $E_{g}$ Variation with Pressure and Temperature}

Eq.(2) is an expression for the variation of the energy gap with temperature for semiconductors under zero pressure. Fig.9. shows the variation of the energy gap with temperature. 


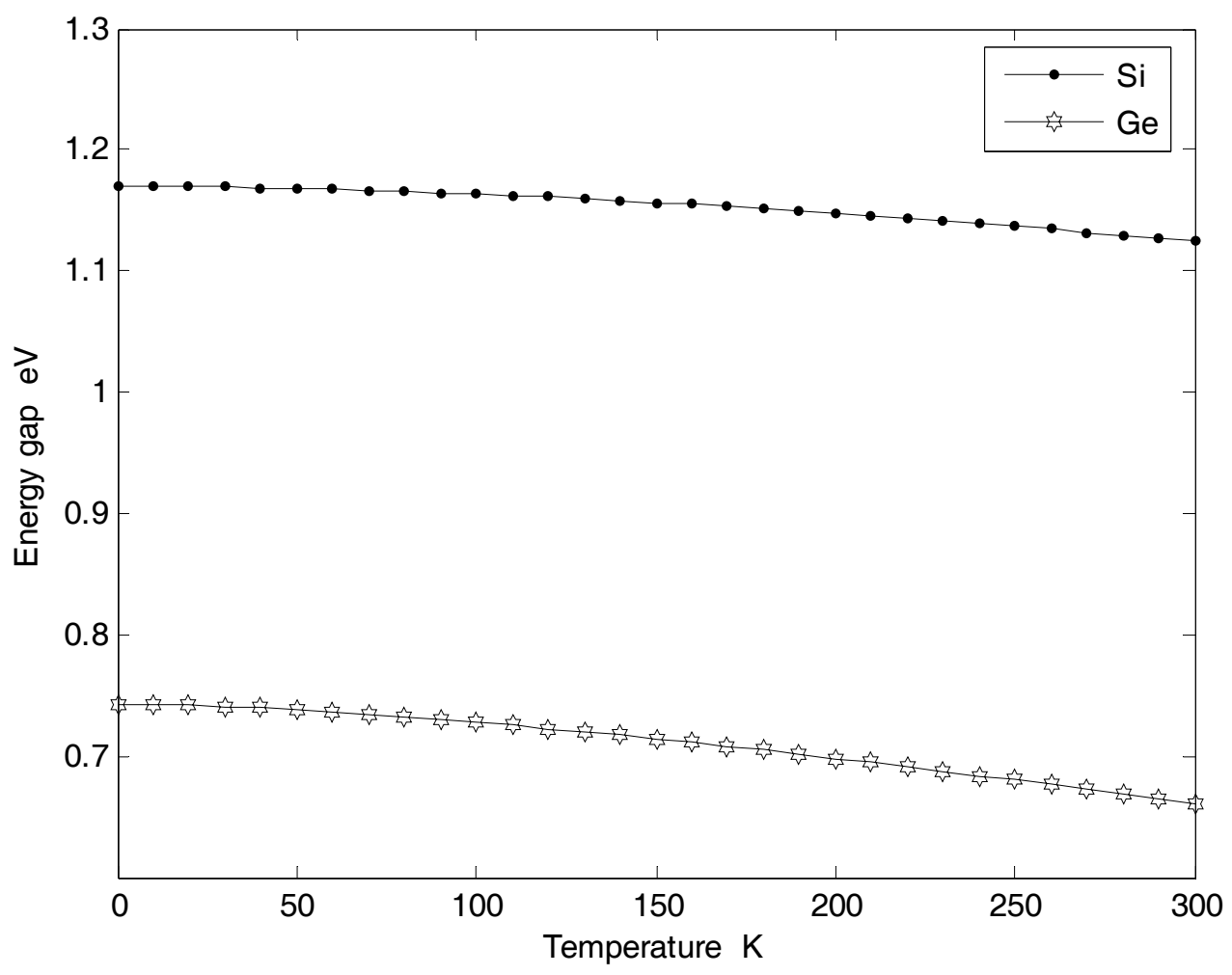

Fig. 9: The variation of energy gap with temperature using Eq.(2) for Si and Ge.

The variation of $E_{g}$ with $T$ at different pressures using Eq.1 for Si and Ge is shown in (Fig.10 and 11).

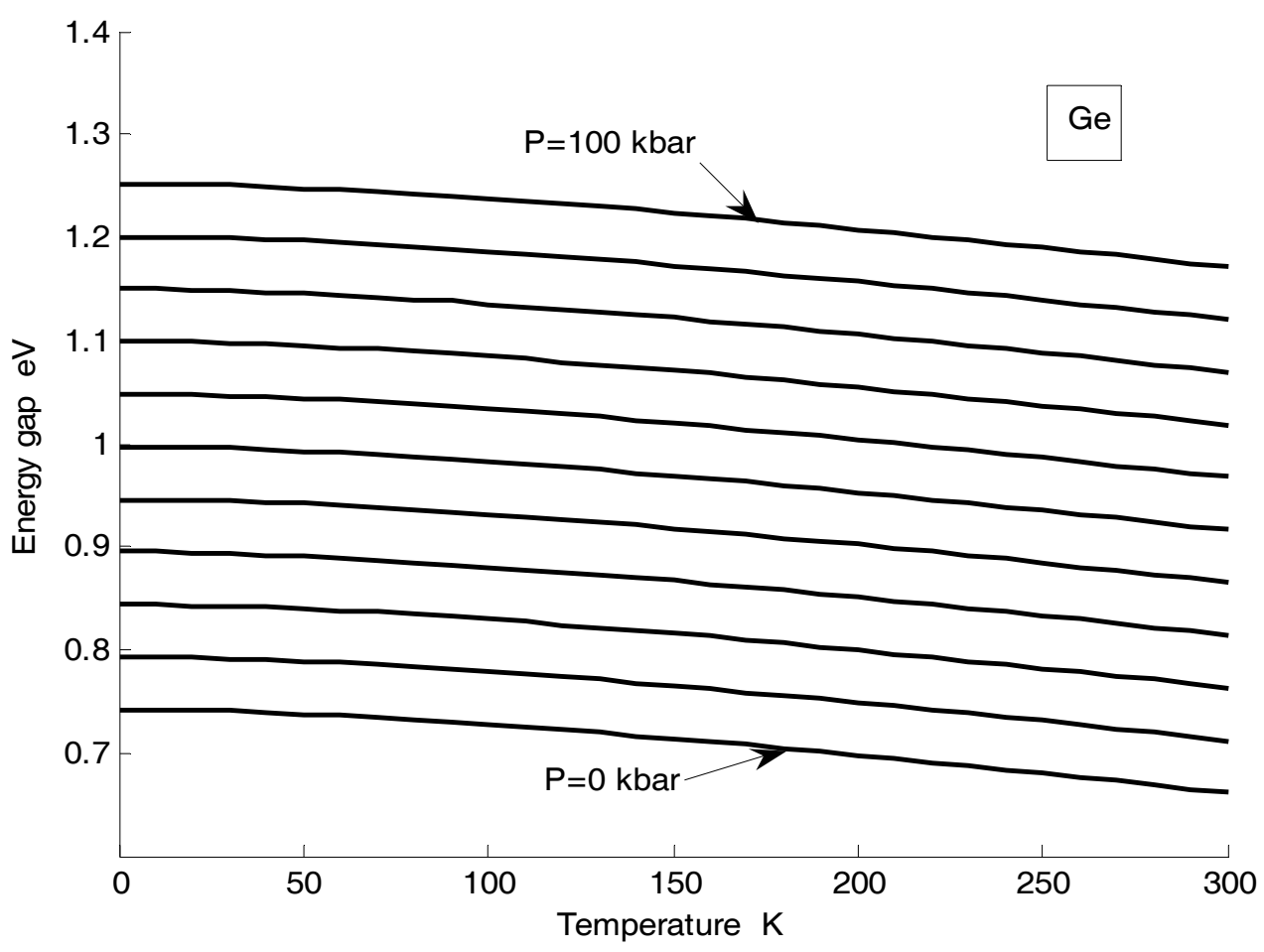

Fig.10: Variation of $E_{g}$ with temperature $T$ at different pressures using Eq.(1) for Ge. 


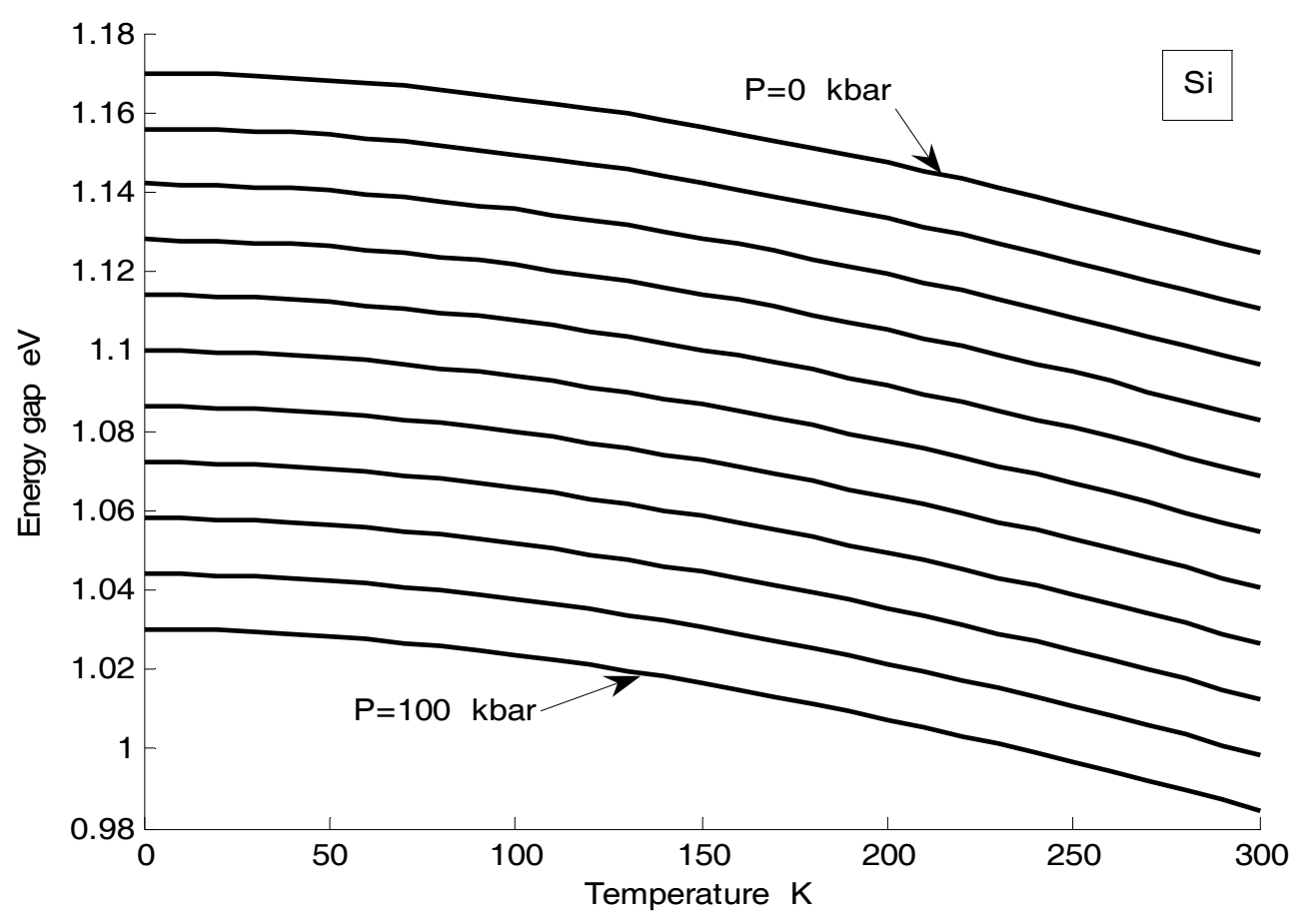

Fig.11: Variation of $E_{g}$ with temperature $T$ at different pressures using Eq.(1) for Si.

Fig.10 shows the effect of the positive value of pressure coefficient for Ge i.e. although $E_{g}$ decreases with increasing temperature, the increase of pressure increases $E_{g}$. Fig.11 shows the effect of the negative value of pressure coefficient for $\mathrm{Si}$, i.e. in addition of decreasing $E_{g}$ with increasing temperature, $E_{g}$ decreases with increasing pressure.

The gradient of the energy gap with temperature for Ge (Fig.10) is greater than that for Si (Fig.11) although opposite of that appears in these figures as a results of the different scales.

\section{REFERENCES}

Al-Sheikh, A. M.; Ahmad, J. F.; Saleh, M. M. (2006). Optimum values of second Grüneisen parameter ( q ) for Iron , Vanadium and Titanium. J. Edu. Sci., 18 (1), 45-52.

Altmann, S.L. (1991). " Band Theory of Solids: An Introduction from the Point of View of Symmetry ". Oxford Science Publications. pp. 153-154.

Angilella, G.G.N.; March, N. H.; Howard, I.A.; Pucci, R. (2008). Pressure dependence of the energy gaps in diamond-type semiconductor, and their III-V analogues such as InSb. J. Physics: Conference series.121, 0322006.

Arezky, H. R.; Trallero-Giner C.; Duque C. A. ; Vazquez G. J. (2009). Optical transition in self-assembled InAs/GaAs quantum lens under high hydrostatic pressure. $J$. Appl. Phys. 105, 044308.

Birch , F. (1947). Finite elastic strain of cubic crystal. Phys. Rev.71, 809-824.

Brad, D. M.; Steven, G.L.; Marvin, L.C. (2010). Electronic and optical properties of body- centered-tetragonal Si and Ge. Phys. Rev. B. 81, 115201. 
Giovane, L.M. (1998). Strain-balanced silicon-germanium materials for near IR photodetection in silicon based optical interconnect. Ph. D. thesis, Department of Material Science and Engineering, Massachusetts Institute of Technology. Massachusetts, pp.73-80.

Jiuxun, S. (2005). A modified Lennard-Jones-type equation of state for solids strictly satisfying the spinodal condition. J. Phys : Condens. Matter 17, L103-L111.

Lee, S.; Dehesa, S.; Dow, J.D. (1985). Theoretical investigation of the pressure dependences of energy gaps in semiconductors. Phys. Rev. B. 32 (2),1152-1155.

Levinshtein, M.E.; Rumyantsev, S.; Shur, M.S.(2001)."Properties of Advanced Semiconduct- or Materials GaN, AlN, InN, BN, SiC, SiGe". A Wiley-Interscience Publication. John Wiley and Sons, Inc., pp.149-161.

Ouyang, G.; Sun, C. Q.; Zhu, W. G. (2009). Atomistic origin and pressure dependence of band gap variation in semiconductor nanocrystals. J. Phys. Chem. C 113, 95169519.

Rushton, P. P. (2002). Towards a Non-Local Density Functional description of exchange and correlation. Ph. D. thesis ; Department of Chemistry and physics, University of Durham. U.K.

Tripathi, P. ; Misra, G.; Goyal, S.C. (2006). Equation of state for group IV-IV semiconductors. Solid State Comunications . 139, 132-137.

Varshni, Y.P. (1967). Temperature dependence of the energy gap in semicondoctors. Physica. 34, 149-154.

Vinet, P. ; Ferrante, J.; Smith, J. R.; Rose, J. (1986). A universal equation of state for solids. J. Phys. Chem. Solid, L467-L473.

Wei, S. ; Zunger, A. (1999). Predicted band-gap pressure coefficients of all diamond and zinc- blend semiconductors: Chemical trends. Phys. Rev. B . 60 (8), 5404-5411. 